\title{
Predictors of Presenting Seizures in Acute Cerebral Vein and Dural Sinus Thrombosis
}

Original Article

Journal of Epilepsy Research pISSN 2233-6249 / elSSN 2233-6257

Received September 26, 2020

Revised November 20, 2020

Accepted December 4, 2020

Corresponding author:

Gourav Goyal, MD, DM, FINS

Department of Neurology, Mahatma Gandhi Medical College and hospital, Tonk Road, near India International School, Ricco Industrial Area, Sitapura, Jaipur, Rajasthan 302022, India

Tel. +91-0141-2770798/2771777/

$$
\text { 2771001-3 }
$$

Fax. +91-0141-2770303/2770900

E-mail; drgauravjaipur@yahoo.com, drgauravjaipur@gmail.com

\author{
Gourav Goyal, MD, DM, FINS ${ }^{1}$, Rambir Singh, MD² \\ ${ }^{1}$ Department of Neurology, Mahatma Gandhi Medical College and Hospital, Jaipur; ${ }^{2}$ Department of Radio-diagnosis, \\ R.N.T MC and MB Hospital, Udaipur, India
}

Background and Purpose: Risk of seizure is significantly higher in cerebral vein and dural sinus thrombosis (CVST) compared to other stroke subtypes. There is paucity of literature on predictors of presenting seizures in CVST. This study was designed to investigate the risk and predictors of seizures in CVST at presentation.

Methods: Total 181 consecutive patients with CVST were retrospectively analyzed.

Results: Total 181 patients with CVST were enrolled (age range, 14 to 96 years; mean age, $34.64 \pm 14.66$ years). A total of 44 patients had presenting seizures. Younger age $(p=0.028)$, involvement of superficial cortical veins $(p=0.016)$, presence of hemorrhagic venous infarct $(p \leq 0.001)$ and involvement of frontal lobe $(p \leq 0.001)$ were significantly related to the presenting seizures on the univariate analysis. The hemorrhagic venous infarct (odds ratio [OR], 4.44; 95\% confidence interval [Cl], 1.89-10.44; $p=0.001$ ) and involvement of the frontal lobe $(\mathrm{OR}, 10.66 ; 95 \% \mathrm{Cl}, 4.02-28.29 ; p \leq 0.001)$ were independently associated with the presenting seizures on the multivariate analysis.

Conclusions: About one fourth of the patients with CVST had presenting seizures. The patients with hemorrhagic venous infarct in the frontal region are more prone to have presenting seizures. (2020;10:74-78)

Key words: Cerebral vein, Cranial sinus thrombosis, Magnetic resonance imaging, Seizures, Superior sagittal sinus, Transverse sinus

\section{Introduction}

Risk of a seizure is significantly higher in cerebral vein and dural sinus thrombosis (CVST) compared to hemorrhagic or ischemic stroke. Seizures are the presenting symptom of CVST in $12-31.9 \%$ of the patients. ${ }^{2}$ Risk factors for early seizures are motor or sensory deficits, cerebral vein thrombosis, supratentorial brain lesions or a hemorrhagic brain lesion on neuroimaging. ${ }^{2-4}$ CVST has varied clinical presentations and may masquerade the other diseases. It may cause delay in the early diagnosis and treatment of CVST. Delayed diagnosis of CVST might be one cause of the development of refractory status epilepticus, which is a serious emergency condition with high mortality and morbidity. ${ }^{5,6}$ There is paucity of literature on predictors of presenting seizures in CVST. In this study, we analyzed the risk and predictors of seizures in CVST at presentation.

\section{Methods}

\section{Subjects}

Patients with CVST in a tertiary care teaching hospital from January 2011 to December 2013 were enrolled in this study. CVST was confirmed by magnetic resonance venography (MRV). Magnetic resonance imaging (MRI) and MRV data of 181 patients with CVST were included in final analysis. Data was extracted from the medical record. Occurrence of seizure at presentation of CVST was noted.

\section{Image analysis}

MRI included diffusion-weighted images, axial T1, axial fast spin-echo (FSE) T2, coronal and sagittal FSE T2, and gradient-echo sequences. Maximum intensity projections (MIPs) were created at the MR operating console for 3D-MR venography data set. The MIP images were viewed in the sagittal, transverse and coronal planes. 


\section{Imaging finding}

The presence of supratentorial parenchymal lesions, their location (frontal, parietal, temporal or occipital), type (non-hemorrhagic or hemorrhagic venous infarction), and presence of intraventricular or subarachnoid hemorrhage (SAH) on magnetic resonance imaging were noted. The location and extent of the thrombosis and the number of sinuses affected on MRV were noted. The direct evidence of cortical veins thrombosis on MRI was also noted.

\section{Statistical analysis}

Numeric values were shown as the mean \pm standard deviation. Demographic, clinical and radiological variables among patients with CVST with or without presenting seizures were analyzed by using chi-square contingency analysis to explore the statistically significant difference. A difference was considered significant at a $p$-value of less than 0.05 . The variables having a two tailed $p$-value of $<0.10$ on univariate analysis were included in the multivariate analysis. The analysis was performed using epi info-7 statistical software (Centers for Disease Control and Prevention, Atlanta, GA, USA).

\section{Results}

Total 181 patients with CVST were enrolled (age range, 14 to 96 years; mean age, $34.64 \pm 14.66$ years). One hundred twenty one patients (66.8\%) were female. A total of 44 patients (24.3\%) had presenting seizures. Out of $44,79.5 \%$ were females. Distribution and types of brain parenchymal lesions in patients presenting with seizures have been shown in Table 1. Most common site of brain paren- chymal lesion was frontal lobe, followed by involvement of the fronto-parietal region. One patient had SAH. Four patients with seizures had no brain parenchymal lesions.

\section{Predictors of presenting seizures}

Younger age $(p=0.028)$, involvement of superficial cortical veins $(p=0.016)$, presence of hemorrhagic venous infarct $(p \leq 0.001)$ and involvement of frontal lobe $(p \leq 0.001)$ were significantly related to the presenting seizures on the univariate analysis (Table 2). There was no significant relation to the site of thrombosis and number of involved cortical superficial and deep venous sinuses to the presenting seizures. Gender $(p=0.06)$, non hemorrhagic venous infarct $(p=0.99)$ and intraparenchymal hemorrhage $(p=0.55)$ were not related to the presenting seizures. On multivariate analysis, the hemorrhagic venous infarct (odds ratio [OR], 4.44; 95\% confidence interval $[\mathrm{Cl}], 1.89-10.44 ; p=0.001)$ and involvement of the frontal lobe (OR, 10.66; $95 \% \mathrm{Cl}, 4.02-28.29 ; p \leq 0.001)$ were independently associated with the presenting seizures (Table 3 ).

\section{Discussion}

In this retrospective analysis, 24.3\% patients with CVST had presenting seizures. Hemorrhagic venous infarct in frontal lobe was the independent predictor of presenting seizures in the CVST. Limited data is available regarding frequency of seizures and clinico-radiological findings of CSVT patients with seizures. In a large prospective study, 39.3\% patients with CVST had seizures at presentation. Patients with presenting seizures also had a higher risk of early

Table 1. Distribution and types of brain parenchymal lesions in patients presenting with seizures

\begin{tabular}{lcccc} 
Site of lesion & $\begin{array}{c}\text { Hemorrhagic venous } \\
\text { infarct }\end{array}$ & $\begin{array}{c}\text { Non hemorrhagic } \\
\text { venous infarct }\end{array}$ & $\begin{array}{c}\text { Intraparenchymal } \\
\text { hemorrhage }\end{array}$ & Total \\
\hline Frontal & $9(33.3)$ & $7(87.5)$ & $3(75)$ & $19(48.7)$ \\
Parietal & $3(11.1)$ & $0(0.0)$ & $0(0.0)$ & $3(7.7)$ \\
Fronto-parietal & $6(22.2)$ & $0(0.0)$ & $0(0.0)$ & $6(15.4)$ \\
Temporo-parietal & $2(7.4)$ & $0(0.0)$ & $0(0.0)$ & $2(5.1)$ \\
Parieto-occipital & $2(7.4)$ & $0(0.0)$ & $0(0.0)$ & $2(5.1)$ \\
Temporo-occipital & $2(7.4)$ & $1(12.5)$ & $1(25)$ & $4(10.2)$ \\
Fronto-temporo-parietal & $1(3.7)$ & $0(0.0)$ & $0(0.0)$ & $1(2.6)$ \\
Temporo-parieto-occipital & $1(3.7)$ & $0(0.0)$ & $0(0.0)$ & $1(2.6)$ \\
Cerebellum and Fronto-parieto-occipital & $1(3.7)$ & $0(0.0)$ & $0(0.0)$ & $1(2.6)$ \\
Total & 27 & 8 & 4 & 39 \\
\hline
\end{tabular}

Values are presented as number (\%).

One patient had or subarachnoid hemorrhage. Four patients with seizures had no brain parenchymal lesions. 
Table 2. Univariate analysis of predictors of presenting seizures in patients with cerebral venous sinus thrombosis

\begin{tabular}{|c|c|c|c|c|c|}
\hline Variable & $\begin{array}{l}\text { Seizure } \\
(n=44)\end{array}$ & $\begin{array}{l}\text { No seizure } \\
(n=137)\end{array}$ & OR & $95 \% \mathrm{Cl}$ & $p$-value \\
\hline Age (years) & $30.43 \pm 9.30$ & $35.99 \pm 15.80$ & - & - & 0.03 \\
\hline Female & 35 & 86 & 2.31 & $1.03-5.19$ & 0.06 \\
\hline Isolated SSS & 11 & 18 & 2.20 & $0.95-5.12$ & 0.10 \\
\hline SSS with other venous sinuses & 23 & 57 & 1.54 & $0.78-3.04$ & 0.29 \\
\hline Isolated TS & 1 & 6 & 0.51 & $0.06-4.34$ & 0.86 \\
\hline TS with other venous sinuses & 29 & 105 & 0.59 & $0.28-1.23$ & 0.22 \\
\hline Isolated SS & 0 & 2 & - & - & 0.98 \\
\hline SS with other venous sinuses & 27 & 92 & 0.78 & $0.38-1.57$ & 0.60 \\
\hline Isolated straight sinus & 0 & 1 & - & - & 0.55 \\
\hline Straight sinus with other venous sinuses & 7 & 26 & 0.81 & $0.32-2.01$ & 0.82 \\
\hline Straight sinus, internal cerebral veins and vein of gallen & 0 & 3 & - & - & 0.76 \\
\hline Internal cerebral veins and vein of gallen & 0 & 2 & - & - & 0.98 \\
\hline Involvement of superficial cortical veins & 4 & 1 & 13.6 & $1.48-125.16$ & 0.02 \\
\hline All superficial and deep venous sinuses & 6 & 14 & 1.39 & $0.50-3.86$ & 0.72 \\
\hline Hemorrhagic venous infarct & 27 & 41 & 3.72 & $1.83-7.55$ & $<0.01$ \\
\hline Non hemorrhagic venous infarct & 8 & 27 & 0.91 & $0.38-2.17$ & 0.99 \\
\hline Intraparenchymal hemorrhage & 4 & 7 & 1.86 & $0.52-6.67$ & 0.55 \\
\hline Intraventricular hemorrahge & 0 & 1 & - & - & 0.55 \\
\hline Subarachnoid hemorrhage & 1 & 0 & - & - & 0.55 \\
\hline Frontal & 19 & 10 & 9.65 & $4.01-23.22$ & $<0.01$ \\
\hline Parietal & 3 & 3 & 3.27 & $0.64-16.82$ & 0.31 \\
\hline Occipital & 0 & 4 & - & - & 0.58 \\
\hline Fronto-temporal & 0 & 4 & - & - & 0.58 \\
\hline Fronto-parietal & 6 & 19 & 0.98 & $0.37-2.63$ & 0.83 \\
\hline Temporo-parietal & 2 & 4 & 1.58 & $0.28-8.95$ & 0.97 \\
\hline Parieto-occipital & 2 & 6 & 1.04 & $0.20-5.35$ & 0.71 \\
\hline Temporo-occipital & 4 & 4 & 3.33 & $0.79-13.90$ & 0.19 \\
\hline Fronto-temporo-parietal & 1 & 1 & 3.16 & $0.19-51.65$ & 0.98 \\
\hline Temporo-parieto-occipital & 1 & 5 & 0.61 & $0.07-5.40$ & 0.97 \\
\hline Bilateral thalamic & 0 & 6 & - & - & 0.35 \\
\hline Bilateral thalamo-capsuloganglionic & 0 & 4 & - & - & 0.58 \\
\hline Bilateral caudate nuclei & 0 & 1 & - & - & 0.55 \\
\hline Bilateral thalamic and fronto-parietal & 0 & 1 & - & - & 0.55 \\
\hline Cerebellum & 0 & 2 & - & - & 0.98 \\
\hline Cerebellum and fronto-parieto-occipital & 1 & 1 & 3.16 & $0.19-51.65$ & 0.98 \\
\hline
\end{tabular}

Values are presented as mean \pm standard deviation or number.

OR, odds ratio; $\mathrm{Cl}$, confidence interval; SSS, superior sagittal sinus; TS, transverse sinus; SS, sigmoid sinus.

Table 3. Multivariate analysis of predictors of presenting seizures in patients with cerebral venous sinus thrombosis

\begin{tabular}{lcrrr}
\hline Variable & OR & $95 \% \mathrm{Cl}$ & $p$-value & Regression coefficient \\
\hline Hemorrhagic venous infarct & 4.44 & $1.89-10.44$ & 0.001 & 0.21 \\
Frontal & 10.66 & $4.02-28.29$ & $<0.001$ & 0.45 \\
\hline
\end{tabular}

$\mathrm{OR}$, odds ratio; $\mathrm{Cl}$, confidence interval. 
seizures. Seizures in CVST can cause neurologic and systemic deterioration, status epilepticus and death although in the International Study on Cerebral Vein and Dural Sinus Thrombosis (ISCVT) cohort seizures were not an independent predictor of death and/or dependency. ${ }^{2,3,8}$ In this multicenter study, supratentorial lesion in CVST was associated with 5.10 times higher risk of presenting seizures. ${ }^{9}$ Similarly in a other retrospective analysis by Kalita et al., ${ }^{10}$ supratentorial lesion was associated with more than 4.67 times higher risk of seizures. In our study, frontal lobe involvement in CVST was 10.66 times more likely associated with presenting seizures. Concerning risk factors for presenting seizures in CVST, lesion anterior to the central sulcus and focal deficits are reported to be associated with seziures. ${ }^{11}$ Hemorrhagic lesion due to CVST commonly presents with seizures. ${ }^{2}$ Parenchymal hemorrhagic lesion, often cortical, results from local venous congestion. Such lesions are the likely cause of seizure activity. The mechanism of seizure in hemorrhagic lesion is not well understood. Blood metabolites such as hemosiderin may cause a focal cerebral irritation leading to seizures as shown in experimental animal models. ${ }^{12,13}$

In a prospective study of 194 consecutive patients with acute CVST, $44.3 \%$ of patients had early symptomatic seizures. Motor deficit, intracranial hemorrhage and cortical venous thrombosis were independent predictors of early epileptic seizures. ${ }^{3}$ The increased risk of seizures in patients with motor deficits points toward underlying damage to the motor cortex. The pooled analysis of grouped data from the Venous Thrombosis Portuguese Collaborative Study Group, ISCVT, and the German studies confirm that focal signs (aphasia and motor deficits), the location of CVT (superior sagittal sinus and cortical vein), and supratentorial parenchymal lesions are associated with a higher risk of presenting seizures. ${ }^{7}$ Thrombosis of the superior sagittal sinus and cortical veins, which drain venous blood from the upper convexity of the brain, including the motor and sensory cortices, can explain higher association of presenting seizures with focal deficits. Risk of acute symptomatic seizure (ASS) was repoted to have 2.7 times higher in hemorrhagic infarction compared to without hemorrhage. Seizure risk was higher in anterior circulation compared to posterior circulation (10.7\% vs. $4.7 \%)$. $^{14}$ The higher frequency of seizure has been reported in patients with straight sinus or cerebral vein thrombosis. ${ }^{7}$ In a recent review, authors have evaluated incidence, characteristics, predictors, treatment, and prognosis of acute and late seizures in patients with CVST. The incidence had been reported in a wide range of $6.9-76 \%$ for ASS and $4-16 \%$ for post CVST epilepsy (PCE). ASS commonly occurred in patients with loss of consciousness, focal neurological deficits, supratentorial lesions and thrombosis in superior sagittal sinus, straight sinus, and cortical veins. PCE had been predisposed by occurrence of ASS, motor deficit, and supratentorial lesions, particularly hemorrhage. ${ }^{15}$ In the present study, there is no significant relation to the site of thrombosis and number of involved cortical superficial and deep venous sinuses to the presenting seizures. Similar reults have been shown in the study by Kalita et al. ${ }^{10}$

\section{Limitations}

The main limitation of the present study is its retrospective nature. Other limitations are single center study, lack of etiology, outcome and follow up data. Single center study may cause case selection bias. Reporting by single radiologist in the present study may also cause bias in the interpretation.

About one fourth of the patients with CVST had presenting seizures. The patients with hemorrhagic venous infarct in the frontal region are more prone to have presenting seizures.

\section{Conflict of Interest}

The authors declare that they have no conflicts of interest.

\section{References}

1. Conrad J, Pawlowski M, Dogan M, Kovac S, Ritter MA, Evers S. Seizures after cerebrovascular events: risk factors and clinical features. Seizure 2013;22:275-82.

2. Ferro JM, Correia M, Rosas MJ, Pinto AN, Neves G; Cerebral Venous Thrombosis Portuguese Collaborative Study Group[Venoport]. Seizures in cerebral vein and dural sinus thrombosis. Cerebrovasc Dis 2003;15: 78-83.

3. Masuhr F, Busch $M$, Amberger $N$, et al. Risk and predictors of early epileptic seizures in acute cerebral venous and sinus thrombosis. Eur J Neurol 2006;13:852-6.

4. Preter M, Tzourio C, Ameri A, Bousser MG. Long-term prognosis in cerebral venous thrombosis. Follow-up of 77 patients. Stroke 1996;27:243-6.

5. Myint PK, Staufenberg EF, Sabanathan K. Post-stroke seizure and post-stroke epilepsy. Postgrad Med J 2006;82:568-72.

6. Rumbach L, Sablot D, Berger E, Tatu L, Vuillier F, Moulin T. Status epilepticus in stroke: report on a hospital-based stroke cohort. Neurology 2000;54:350-4.

7. Ferro JM, Canhão P, Bousser MG, Stam J, Barinagarrementeria F; ISCVT Investigators. Early seizures in cerebral vein and dural sinus thrombosis: risk factors and role of antiepileptics. Stroke 2008;39:1152-8.

8. Stolz E, Rahimi A, Gerriets T, Kraus J, Kaps M. Cerebral venous thrombo- 
78 Journal of Epilepsy Research Vol. 10, No. 2, 2020

sis: an all or nothing disease? Prognostic factors and long-term outcome. Clin Neurol Neurosurg 2005;107:99-107.

9. Ferro JM, Canhão P, Stam J, Bousser MG, Barinagarrementeria F; ISCVT investigators. Prognosis of cerebral vein and dural sinus thrombosis: results of the international study on cerebral vein and dural sinus thrombosis (ISCVT). Stroke 2004;35:664-70.

10. Kalita J, Chandra S, Misra UK. Significance of seizure in cerebral venous sinus thrombosis. Seizure 2012;21:639-42.

11. Bousser MG, Ross Russell RR. Cerebral venous thrombosis. In: Warlow CP, Van Gijn J, eds. Major Problems in Neurology. Vol. 33. London: Saunders,
1997.

12. Küçükkaya $B$, Aker $R$, Yüksel $M$, Onat $F$, Yalçin AS. Low dose MK-801 protects against iron-induced oxidative changes in a rat model of focal epilepsy. Brain Res 1998;788:133-6.

13. Willmore L. Post-traumatic seizures. Neurol Clin 1993;11:823-34.

14. Beghi $E$, D'Alessandro $R$, Beretta $S$, et al. Incidence and predictors of acute symptomatic seizures after stroke. Neurology 2011;77:1785-93.

15. Mehvari Habibabadi J, Saadatnia M, Tabrizi N. Seizure in cerebral venous and sinus thrombosis. Epilepsia Open 2018;3:316-22. 